\title{
LA PEDAGOGÍA DEL ARTE DE M. B. COSSÍO: UN MODELO DE EDUCACIÓN INCLUSIVA EN LA UNIVERSIDAD A TRAVÉS DEL VIDEO PARTICIPATIVO Y EL APS
}

\author{
THE PEDAGOGY OF ART BY M. B. COSSÍO: AN INCLUSIVE \\ EDUCATION MODEL AT THE UNIVERSITY THROUGH \\ PARTICIPATORY VIDEO AND APS
}

\author{
DELIA MANZANERO \\ Universidad Rey Juan Carlos de Madrid
}

Recibido: 03/10/2020 Aceptado: 20/01/2021

\section{RESUMEN}

Este artículo trata de mostrar la fecundidad de la pedagogía como arte de M. B. Cossío por su eficacia demostrada en la adquisición de contenidos relacionados con el derecho por parte de personas con discapacidad intelectual. A tal efecto, se describen los resultados de una intervención educativa donde se empleó el método del Video participativo en un proyecto de $\mathrm{ApS}$, como herramienta de cambio para promover el pensamiento inductivo e introducir una visión de responsabilidad y compromiso social con el fin de educar en la diversidad, el respeto y la valoración de la autonomía individual de los propios educandos.

Palabras clave: arte, ApS, Cossío, derecho, pedagogía 


\section{ABSTRACT}

This article seeks to show the fecundity of pedagogy as an art of M. B. Cossío due to its proven effectiveness in the acquisition of content related to law by people with intellectual disabilities. To this end, it describes the results of an educational intervention where the participatory Video method was used in a Service-Learning project (ApS), as a tool for change to promote inductive thinking and introduce a vision of responsible and social commitment in order to educate in diversity, respect and the appreciation of the individual autonomy of the students themselves.

Keywords: art, ApS, Cossío, law, pedagogy.

\section{INTRODUCCIÓN: LA PEDAGOGÍA DEL ARTE DE M. B. COSSÍO}

La obra pedagógica de Manuel Bartolomé Cossío, considerado hoy día como uno de los principales innovadores en la Historia de la Educación española contemporánea, constituye una oportunidad crucial para comprender el influjo que tuvo su moderna concepción de la educación basada en la enseñanza del arte, la enseñanza técnica y la educación popular, entre otras notas pedagógicas que revolucionaron el sistema educativo español, y que establecen grandes líneas de actuación que luego se han desarrollado en programas educativos contemporáneos. Bajo la influencia de M. B. Cossío y, transcurridos muchos años después de su muerte, encontramos su inspiración en casi toda la literatura pedagógica en lengua castellana, un influjo general sin el cual no se comprendería el proceso de la modernización del sistema educativo en los siglos XIX y XX en España, ni acaso se explicarían no pocas esenciales manifestaciones de nuestro modelo educativo actual.

Su dilatado radio de acción mantuvo siempre un amplio influjo, al menos, en dos direcciones fundamentales: tanto por el influjo de su personalidad, que signó con su huella buena parte de la historia española y que logró influir, tanto en los proyectos de reforma e instrucción de su época y, por extensión, de la nuestra - pues muchos de sus principios educativos que han pasado a ser hoy patrimonio común de los patrimonios educativos de nuestro tiempo-, como por el influjo de varias de sus innovaciones educativas como pedagogo en la esfera social, tras haberlas probado como maestro en las aulas de la Institución Libre de Enseñanza; un influjo que, al mismo tiempo, se hace notar por su marcada proyección hacia lo social, en su aplicación a sectores sociales que tradicionalmente habían quedado silenciados o excluidos de los ámbitos educativos, algo 
que logró llevar a cabo en virtud de su actividad como Director del Museo Pedagógico Nacional y como presidente de las Misiones Pedagógicas.

Esta proyección social partía de un modelo de escuela abierta que desborda las instituciones y que no se puede encerrar en el academicismo escolar ni los recintos cerrados del aula; un tipo de educación total, que tampoco podría ser considerado un derecho privativo de la infancia, sino que se hacía extensible a todas las edades y condiciones sociales, incluyendo tanto a la juventud obrera como a aquellas zonas rurales donde los ciudadanos gozaban de menos estímulos culturales; algo que cristaliza en la escuela ambulante de las Misiones Pedagógicas en 1931, donde se puso en práctica, quizá por primera vez en España, una pedagogía activa que estuvo en íntimo contacto con la vida y con el arte: la pedagogía de la intuición, en la expresión acuñada por Pestalozzi y Fröbel, con un especial énfasis en la educación de la sensibilidad (la pintura, la música, el teatro, el cine y el arte en general) y donde además aportaba el estímulo de las habilidades manuales (dibujo, carpintería, jardinería,...). Este método intuitivo es retomado y enriquecido gracias a la obra del genio educador, Manuel Bartolomé Cossío, en su pedagogía entendida como arte.

El concepto de educación como arte no se resuelve ni se trata únicamente de una mera técnica de educación, sino que alcanza en la obra de Cosío el sentido de bella arte al hacer de la educación una creación, una recreación personal por la cual el agente principal es el educando mismo. La originalidad de esta doctrina frente a otras realizaciones pedagógicas de su tiempo reside en su propósito de enseñar al alumno a ser artista de su propia vida, a ser artífice de su pensamiento, a reproducir su vida artísticamente a través de las bellas artes y de los medios que le procura su educador, pero, sobre todo, de su conocimiento directo de la realidad y del acontecer del mundo. Esta acción educativa se ejecuta en tres niveles complementarios: en el plano de la intuición, donde el alumno percibe su propia realidad, medio primario de toda educación. En el plano artístico, basado en la representación o la imagen que nos traslada el arte. Y por último, en el plano simbólico donde opera ya la representación ideal que nos permite traducir la realidad en lenguaje artístico y construir la cultura.

El objetivo de este modelo de escuela activa es despertar en los alumnos su afición por el arte y la literatura, permitiendo que se abran a la realidad estéticamente, mediante la contemplación de dichos elementos, pero también mediante la acción y la comprensión crítica de la vida (Maya y Patiño 2020, 17). Se trata pues de hacer ver la función superior que tiene el arte en la educación del hombre, en la formación de su conciencia vital, en su capacidad para operar cambios profundos en el ser humano, a través de la pasión, de la belleza, de la liberación 
y la catarsis que puede producir el goce estético. En esto radica pues la función del maestro que, tal y como encarnó el propio Cossío en su hacer educativo, debía ser ante todo un artista educador, capaz de hacer que sus alumnos se abran al gozo estético, que sean capaces de hacer de su propia vida una obra de arte, pues el arte supremo es el arte de saber vivir, ennoblecido a través de la belleza y puesto en contacto con los mejores ejemplos que se dejan traslucir en el ideal educativo.

Lo que propone Cossío con esta doctrina es una defensa de la educación como El arte de saber ver (1879), para lo cual era preciso romper la rutina acumulada a través de siglos y enseñar a ver, a saber ver, a pensar sobre lo que se $v e$, apropiándonoslo y asimilándolo a la ley de desarrollo de la propia personalidad, lo cual respondía muy bien al temperamento artístico de Cossío. La conclusión a que nos llevan todos estos planteamientos es que la educación debe conducirnos a hacer de nosotros mismos nuestra propia obra de arte. Cossío plantea así una moderna concepción de la "pedagogía" para indicar que con ella no se refiere a una doctrina aislada en aulas que procurase una instrucción entendida como mera acumulación de datos, sino a un proyecto mucho más ambicioso que se propone formar hombres y que responde mejor al novedoso concepto de educación que había aprendido de su maestro Francisco Giner de los Ríos. Aquí vemos pues cómo la pedagogía de Cossío, entendida como arte, afirma que debemos dar un paso del mirar al ver, que es el paso que da el maestro cuando en vez de limitarse a instruir, se dedica a educar. De ahí que Cossío prefiriera reservar la palabra "educador" para referirse a la tarea reformadora y al importante compromiso social de que estaba dotada la educación en Giner, cuyo proyecto pedía educar antes que instruir, es decir, formar hombres que desarrollen su propia personalidad autónomamente y que promuevan una reforma social efectiva, responsable y estable.

Muchas de estas ideas pedagógicas cumplieron un relevante papel en sentar las bases reformistas que han permitido posteriormente y que han hecho posible hoy una evolución de verdadero sentido progresivo. Si bien, sus aportaciones no pueden separarse del fenómeno pedagógico que desencadenó la propia Institución Libre de Enseñanza, cuya complejidad y amplitud desborda el estudio de su propia obra personal y nos permite contextualizar mejor algunos de sus aspectos más notables en la reforma de la enseñanza. Por esta razón, reseñaremos a continuación las razones de la creación del Institución Libre de Enseñanza, qué factores coyunturales y qué obstáculos sociales explican el nacimiento y el espíritu de la ILE como institución privada, y por qué su proyecto educativo de convertir la escuela en educadora de la libertad, de hacer de ella una institución democrática, viva, en algo abierto a la naturaleza, al arte, etc. se ha convertido 
hoy en un referente en la defensa del derecho a la educación pública, igualitaria, democrática e inclusiva.

\section{LA INSTITUCIÓN LIBRE DE ENSEÑANZA Y EL PROYECTO DE SO- CIALIZACIÓN DE LA ENSEÑANZA}

La obra de la Institución Libre de Enseñanza es difícilmente comprensible sin la compenetración intelectual y afectiva de don Manuel Bartolomé Cossío y don Francisco Giner de los Ríos; el primero, filósofo y jurista, el segundo, contemplativo y artista, pero ambos unidos en su faceta educadora, social y su fondo insobornablemente liberal. A continuación, ahondaremos en algunos aspectos esenciales de la faceta educativa y pedagógica de Giner y Cossío, a través de la historia de la Institución Libre de Enseñanza, un centro de educación que fue, como es bien sabido, el principal fruto de la teoría pedagógica gineriana y que representa el inicio de esa búsqueda de nuevos espacios donde desarrollar su labor académica y defender los valores tan esenciales de la libertad de cátedra y la libertad de la ciencia. Un problema de educación que se aquí se aborda desde la función del maestro; ámbito que quizá a alguien le pudiera parecer modesto, pero que es condición de posibilidad para la construcción de una vida plena de significación y para sentar las bases de una sociedad democrática. En particular, lo abordaremos desde la función de uno de los maestros y filósofos más completos formado en la escuela krausista, Giner de los Ríos, por su función como maestro de maestros en un momento crítico de modernización de la ciencia y la pedagogía española (Lafronte 1918, 283).

La ILE, hija del movimiento liberal que tan preclaramente simboliza Giner de los Ríos, surge como una institución privada que recoge en sus estatutos fundacionales los principios de la libertad e inviolabilidad de la ciencia y la independencia del sistema educativo. La necesaria vinculación que la ILE establece entre educación y libertad como principal instrumento de transformación social, se tradujo en los principios modernizadores y antidogmáticos que consagraban la libertad en la enseñanza y cuya realización práctica tomó cuerpo en proyectos como la educación popular, la investigación internacional $\mathrm{y}$, por supuesto, la libertad de cátedra del profesorado, para la cual era preciso la creación de una institución libre de ataduras legislativas.

Consideramos pertinente recordar este momento fundacional porque en los estatutos de la ILE se ponen ya de relieve dos de las características principales del ideario institucionista que fueron cruciales para sentar las bases de una 
renovación a fondo de la educación: por un lado, su vocación cosmopolita y multidisciplinar, y por otro lado, -tal y como reza el artículo $1^{\circ}$ de sus estatutosla defensa del "principio de la libertad e inviolabilidad de la ciencia y de la consiguiente independencia de su indagación y exposición respecto de cualquiera otra autoridad que la de la propia conciencia del Profesor" (VV.AA. 1876, 5) ${ }^{1}$.

Es importante recordar que tanto la obra de Giner como la de Cossío y sus seguidores institucionistas, está marcada por un contexto adverso -que no era otro sino el de la frustración con la Restauración canovista-, por una gran inestabilidad política y por una onerosa falta de libertad en las Universidades, todo lo cual trajo consigo dos consecuencias básicas: por un lado, su silenciamiento en la vida académica oficial -pues varios profesores krausistas fueron forzosamente separados de sus cátedras, alejados de las aulas, desterrados, y algunos incluso encarcelados por introducir el darwinismo y las más modernas teorías europeas en España-; mientras que, por otro lado, se les dotó de voz en la Institución Libre de Enseñanza (1876), donde pudieron seguir desarrollando su labor académica y defender los valores de la autonomía universitaria y la libertad de cátedra, un derecho que hoy en día consideramos como derecho humano fundamental y que se consolida en la historia de la educación española de la mano de los sectores más progresistas y de las ideas krausistas sobre la libertad de la ciencia.

Nos parecía importante recordar primera etapa de la ILE (de 1876 a 1881), pues probablemente este es el momento más combativo de la Institución. Es el momento de la intransigencia política del Estado, que llevó al marqués de Orovio a firmar el decreto de expulsión de la Universidad a un numeroso grupo de profesores, según hemos visto antes al hablar del contexto histórico. Esa circunstancia hizo que la Institución funcionara durante esta primera etapa más como una especie de Universidad privada que como otra cosa, pues tuvo que buscar sus propios centros de formación y su propia auto-financiación para poder salvaguardar el principio de la libertad de la ciencia, que por aquel entonces no se respetaba en la Universidad Central de Madrid.

Se sustraía así la ILE a la esfera de acción del Estado y daba un primer paso hacia la independencia de la investigación científica y de la función del profesor, cuya libertad de cátedra trataron de salvaguardar en todo momento, según el

1 Para un estudio profundo sobre el nacimiento y el espíritu de la ILE, recomendamos encarecidamente la lectura de los textos y documentos de la época publicados en el Boletín de la Institución Libre de Enseñanza (BILE) en su primera edición histórica (1877-1936). El BILE conoció una segunda época bajo la dirección del hoy considerado el gran historiador de la ILE, Antonio Jiménez Landi, donde se recobra la memoria histórica de la publicación. Por esta razón, es muy recomendable la lectura de sus cuatro volúmenes sobre La Institución Libre de Enseñanza y su ambiente (Jiménez 1996). 
"memorable decreto que afirmó para siempre la libertad de la Ciencia y la Enseñanza" (Los fideicomisarios de Sanz Del Río 1871, 7). Un derecho que se consagra en la segunda etapa de la ILE (que abarca los años de 1881 a 1907), un periodo que da comienzo de modo explícito en el año 1881 con la firma de un decreto de restitución a la Universidad de los profesores expulsados (Cossío 1919 174-177). Este decreto constituye un momento importante de nuestra historia docente, pues no sólo deshace una injusticia mediante la reposición de dichos profesores a sus cargos, sino que establece el principio de la libertad de cátedra como derecho inviolable del profesorado, un momento nada desdeñable para nuestra historia docente, cuya filosofía inspiradora continúa vigente, de ahí la importancia de este decreto de 1881, que constata algo muy significativo al afirmar que: "la libertad es a la vida de la Ciencia y el Arte lo que el oxígeno a la existencia de las especies vegetales y animales" (Revista El Socialista 1926, 382).

Donde adquiere todo su sentido este alejamiento de la ILE y la filosofía educativa krausista de las concepciones centralizadoras estatales, es en el reconocimiento de la personalidad que late en cada una de las asociaciones humanas, $\mathrm{y}$, en consecuencia, en la posibilidad de autogobierno que corresponde a cada una de ellas en su ámbito de acción. En ello radica quizá el fondo más democrático de la filosofía liberal que enarbola la filosofía educativa krausista, y cuyo principal efecto consistió en otorgar un importante papel a las formaciones sociales que vertebran la pluralidad existente en la sociedad y su empeño tan moderno de hacer residir originariamente el poder público en la comunidad, a través de la socialización de la enseñanza y del derecho a la educación.

Efectivamente, a pesar del origen claramente liberal de la ILE, el institucionismo apostaba por una visión más humana de la educación y de la sociedad, por tanto, el blanco al cual apuntaba no podía reducirse a la formación de unos jóvenes pudientes, sino que a este proyecto subyacía un objetivo de mayor alcance: la socialización de la enseñanza. Como lo expresara el historiador y jurista, Rafael Altamira, una de las personalidades claves y determinantes para comprender la faceta educadora de Giner, éste

estuvo siempre lejos de exclusivismos y cerramientos aristocráticos reservados a unos cuantos elegidos con desprecio de todos los que no llenan el máximo de las condiciones requeridas. Esas selecciones están bien en los cenáculos que buscan la perfección moral del individuo apartado del mundo, pero no en la obra educativa que tiende a producir, especialmente, una acción social (Altamira 2015, 117). 
Autores institucionistas como Cossío, Giner, Azcárate, Posada, y, en general, todos los intelectuales españoles sensibilizados con los fines científicos y educativos de la Institución Libre de Enseñanza y la JAE, emprendieran la labor de modernizar la filosofía educativa española a través de la función del maestro en las escuelas y en las Universidades españolas. Así pues, estos esfuerzos por reivindicar la libre discusión frente al dogmatismo reaccionario, por propugnar la educación popular en forma de actividades de extensión universitaria y promover las comunicaciones con otras Universidades nacionales e internacionales para tejer una auténtica sociedad científica en pro de la organización y la autonomía, probablemente representan el medio más interesante y la actitud más progresista que esta sociedad era capaz de generar.

Como se pone de manifiesto en las citadas reformas pedagógicas, la educación en el sistema krausista asume una importante responsabilidad social y sus proyectos educativos constituyen visiblemente un valioso acercamiento cultural de cierto sector de la clase burguesa española de finales del siglo XIX, que estaba consciente de su papel de minoría, consecuente y responsable; y que, a pesar de estar sumida en una sociedad con fuertes antagonismos, se mostraba especialmente abierta a la problemática social, señeramente, en su pretensión era dejar de ser minoría a través de la implementación de reformas educativas y sociales que empezaran a ser visibles en todos los frentes de la vida del país.

De acuerdo con este principio de socialización de la enseñanza, el fin de toda pedagogía debía ser primar la educación, como forja de actitudes creadoras, frente a la mera instrucción, entendida como aprendizaje de unas disciplinas sistemáticas y compartimentadas. Esto lo decía muy bien Cossío, cuando afirmaba que "hay que hacer del niño, en vez de un almacén, un campo cultivable, y de cada cosa una semilla y un instrumento para su cultivo" (Cossío 1966, 14). El verdadero objetivo de la enseñanza debe ser la educación, porque mientras que la instrucción tiende a dar información y a almacenar conocimientos, la educación se propone formar hombres que desarrollen su propia personalidad.

La nueva visión pedagógica propuesta dictaba que la educación debía ser integral y continua, para completar su desarrollo armónico mediante el cultivo del arte, el juego colectivo, los trabajos manuales, la educación física, con igual cuidado al cuerpo y al espíritu, con una especial atención a las emociones, a los afectos, a los principios y los sentimientos de respeto hacia la dignidad humana, la compasión hacia los más vulnerables, etc. En definitiva, una formación humana y social, que prepare al niño y a la niña en el ideal para la humanidad, por decirlo en términos krausistas. 
Otro principio clave del institucionismo es la aplicación del método intuitivo, mediante el cual el educando entra en contacto con las realidades vivas y va desarrollando su propio proceso cognoscitivo y humano. Al mismo tiempo que mediante el contacto socrático con el maestro, vimos cómo éste se convierte en partero o comadrón de los conocimientos del alumno. Ahora bien, el método intuitivo no debe confundirse simplemente con una enseñanza empírica o positivista; en el método intuitivo entra, desde luego, la observación sensible, pero también la introversión, el pensar por cuenta propia, la actividad crítica y creadora, el impulso hacia el trabajo propio y personal,... en una palabra, todo aquello que contribuye a que el alumno perciba intuitivamente el contenido de la enseñanza a través de la realidad, y no por medio de abstracciones y generalizaciones cuyo sentido resulta a veces difícil de precisar. El método intuitivo es, en definitiva, el método activo, con el que el estudiante puede identificarse fácilmente, y que supone la inversión de la didáctica tradicional -y no tan tradicional-, haciendo preceder el interés y el descubrimiento del educando a la lección del maestro, la cual pasa ahora a ser un complemento final.

Pero la filosofía krausista todavía va más allá al reivindicar la educación como un derecho legítimo que debe extenderse a lo largo de toda la vida del individuo. De acuerdo con el sistema jurídico krausista, siendo la adquisición de la ciencia un fin común a todos los hombres, debe reconocerse la existencia de un derecho a la educación, tesis que ha ganado hoy en día un gran poder de convicción en las políticas europeas contemporáneas en materia de educación (Gómez 1983), si bien su implantación no ha resultado del todo satisfactoria (Meix 2014). La formación sería un bien del que deben disfrutar los ciudadanos de todas las edades y del que no se puede prescindir en ningún momento. Este Derecho a la educación es esencialmente un deber inmanente que puede hacerse hasta cierto punto transitivo, en razón de determinados fines sociales, pues "cada hombre tiene derecho de educarse sin ser en ello estorbado por los demás" (Giner 1917, 131). El derecho a la educación y la formación, en tanto que derecho fundamental de todo hombre, se revela pues en la perspectiva institucionista, como uno de los instrumentos más eficaces de luchar contra la discriminación social y constituye así la mejor herramienta para garantizar la igualdad de oportunidades (Nieto 1933, 321-324)2.

2 Aunque no sería la única herramienta, pues como hace ver Pierre Bourdieu, el sistema educativo puede asegurar la perpetuación del privilegio por el solo juego de su propia lógica: "la eficacia de los factores sociales de desigualdad es tal que la igualación de los medios económicos podría realizarse sin que el sistema universitario deje por eso de consagrar las desigualdades a través de la transformación del privilegio social en don o en mérito individual. Mejor aún, habiéndose cumplido con la igualdad formal de 
Así lo expresa Fernando de los Ríos, en su texto "El valor de la educación. Sentido y alcance de la socialización de la enseñanza", donde refiere lo siguiente: "La ruta es clara: la enseñanza ha de ser socializada. El lector se dirá: ¿Cómo puede una democracia burguesa trabajar contra sí? ¿Cómo es posible que, si la socialización de la enseñanza es la condición fundamental para ir creando un régimen superador del capitalismo, se avenga la sociedad capitalista a abrirse a sí misma la sepultura? La respuesta es obvia: la democracia lleva en sí la aspiración a ensanchar sus fronteras, y una vez puesta en marcha políticamente, es pueril todo empeño encaminado a impedir que se extienda a lo social" (De los Ríos 1926: 99). Y continúa más adelante Fernando de los Ríos explicando en qué consistirá la obra krausista de reivindicación del derecho a la educación, haciendo énfasis en el marco europeo en que se desarrolla esta demanda de la divulgación de la enseñanza:

La enseñanza se desenvuelve en Europa juntamente con la línea general de la organización política: fue aristocrática en su etapa inicial, y así, surgen, en los comienzos del XIII, los estudios universitarios para dar satisfacción a los deseos de unos pocos; se ensancha cuando irrumpen nuevas clases, y en su virtud se desprenden de aquéllos los estudios de Humanidades en el Renacimiento, que son origen de lo que posteriormente ha de llamarse segunda enseñanza; intenta democratizarse cuando Europa lo desea, y para ello, al final del XVIII, aparece la escuela primaria con carácter oficial, como función pública; es el siglo XIX, en fin, el que difunde el principio de la obligatoriedad; mas como el liberalismo de esa edad, en su optimismo, identificó la permisión y el mandato jurídico con la realidad, ha sido preciso que la crítica ponga de manifiesto la diferencia entre permitir y ser realmente posible, para que se inicie la fase actual bajo la presión de nuevas masas y nuevos ideales: la socialización de la enseñanza, etapa postrera de la democracia política en la vía de la cultura (De los Ríos 1926, 99).

Nos ha parecido oportuno transcribir este texto de Fernando de los Ríos, con las mismas palabras utilizadas por él, y ello por dos razones: porque es interesante la argumentación apasionada con que defendía estas tesis krausistas del derecho a una educación pública y universal y porque también en el análisis de la terminología y expresiones que utiliza se pueden encontrar claves para clarificar el significado de su pensamiento y de la función que los institucionistas atribuían al maestro.

posibilidades, la educación podría poner todas las apariencias de la legitimidad al servicio de la legitimación de los privilegios" (Bourdieu 2009, 45). 
Para el institucionismo, el maestro puede y debe convertirse también en un aliado obligado en la lucha contra la injusticia. La formación que se imparte en las escuelas puede y debe fomentar entre los individuos el respeto por los derechos humanos, la tolerancia y la equidad. Recordemos aquí el interesante papel preventivo que la educación, y particularmente, la educación en el derecho, cumple dentro de la teoría jurídica krausista (Manzanero 2016).

\section{LA ESCUELA ( $\left.\Sigma X O \Lambda^{\prime} H\right)$ CAMINO DE LIBERACIÓN Y CREATIVIDAD: EL OTIUM FRENTE AL NEGOTIUM}

La concepción que los institucionistas tenían del maestro y de la escuela, consiste pues en poner de manifiesto el problema social derivado de la falta de escolarización de gran parte de la población en su época. A tal efecto, al igual que cada generación y cada momento vital dialoga a su modo con Atenas, Cossío recupera la definición de "escuela" en la Grecia clásica y lo hace con un empeño social, precisamente en aquellas horas bajas, en que se hacía de todo punto necesario recordar que la escuela aristotélica (skholè, $\sigma \chi 0 \lambda \dot{\eta}$, entendida como tiempo libre) era un privilegio únicamente para el disfrute de los ciudadanos libres en la Grecia Clásica, quienes podían disponer por sí mismos de su tiempo para conversar, pensar, para la contemplación, para la evasión, en definitiva, para el ejercicio real y efectivo de su libertad. Esta capacidad del hombre de sustraerse al dominio de la necesidad y de lo útil, para entregarse a las actividades libres y desinteresadas, es invocada por Cosío en sus conferencias en el Ateneo de Madrid y ante un público más amplio de obreros, para hacerles notar que la escuela es un espacio de creación y de liberación positiva y que lo contrario de la libertad de la escuela (skholé) sería el trabajo (a-skholía), que consiste en conseguir lo necesario para la vida, en la mera supervivencia. De ahí la necesidad de que todo el mundo vaya a la escuela, de que estudien aquello que, no sirviendo para ninguna especulación utilitaria, alcanza sin embargo los más altos valores. Cossío reclama el derecho que tiene todo el mundo a disponer de su legítimo tiempo de ocio, y lo hace con la facundia propia de la época:

En la vida hay trabajo. Poco trabajo espiritual y libre, y todavía, por desgracia, mucho de esclavos. Más la escuela no es 'trabajo', sino 'juego. Así lo llamaron los latinos ludus... Y como nadie juega sin estar desocupado, sin llegar a tener ocio, 'ocio' es lo que significa exactamente escuela en Grecia, que creó la palabra. Estudiante, escolar, quiere decir 'ocioso'; porque tener ocio es y ha sido siempre necesario y suprema aspiración del hombre para 'jugar', y más que nada, para estudiar; o sea, saber por saber; contemplar y gozar puramente lo 
bello; perseguir el bien sin egoísmo, es decir, para 'jugar' también con el espíritu, porque eso es jugar, y a eso, y nada más que a eso, debe irse a la escuela (Cossío 1966, 141).

Esta definición de la escuela como espacio de libertad, creatividad y de ocio, es algo que no se debe confundir con la ociosidad infructífera, pues no se trata de una ocupación reposada, sino de una virtud del intelecto que ha de ejercitarse. Para deshacer un posible equivoco, Cossío recurre a la distinción entre otium y negotium, señalando cómo "el otium fue tomado por los cristianos para representar el ideal de los bienaventurados, la contemplación de Dios; de la misma manera que el pueblo griego se entregaba a la contemplación del Bien, de la Belleza y de la Verdad: 'Por esto, en sentido quizás gracioso, podríamos decir que la gloria es una escuela"' (Otero 1994, 102). Resulta interesante consultar también a este respecto el doble sentido de aprender jugando que Bourdieu confiere al término scholé, en su sentido etimológico como "juego", y su conexión posterior con el término "escuela"; un conocimiento liberado pues de todo imperativo material y de las urgencias y necesidades mundanas, frente a otros espacios de trabajo y sumisión (Bourdieu 2009).

Resulta indispensable pues la escuela sea obligatoria $-\mathrm{y}$ no solo en teoríapara todos los niños y para los adultos que se han visto privados de esa oportunidad, pues es la única institución en la que muchas personas encuentran acogida para expresar y poner solución a las carencias culturales, emocionales o sociales que no encuentran en la esfera doméstica, para adquirir el poder necesario para contemplar y juzgar las cosas, para pensar y sentir en ese sentido profundo del juego que Cossío otorga a la educación, un espacio donde pueden recibir una educación vital y existencial que no podrían encontrar en otra parte.

De no hacerlo así, se correría el riesgo de perder esa oportunidad única de impartir unas lecciones vitales básicas que, sin el privilegio que garantiza ese acotado periodo de sus vidas en la escuela. Sin dicha skholé, muchos niños no aprenderían nunca estas lecciones básicas o, en el mejor de los casos, tendrían que aprenderlas por su cuenta en condiciones mucho menos favorables y enriquecedoras, pues como indica Cossío, el juego no acaba con la infancia, "porque el juego es arte y placer estético y la humanidad es bien sabido, diga lo que diga Spencer, que necesita antes que comer divertirse [y añade Cossío, desde un enfoque reeducativo que es pura propedéutica y terapéutica social:] Si el pueblo no se divierte sana y honradamente, ha dicho Doña Concepción Arenal, se divertirá de otro modo, pero se divertirá a toda costa" (Cossío 1906, 22).

Esta base del juego y del ocio está en la raíz de la concepción pedagógica de Cossío y fue aplicado de manera generosa en el marco de la Institución Libre de 
Enseñanza: un tiempo libre creativo y fructífero cuya aspiración era procurar a toda persona el tiempo de ocio para que pueda dedicarse a las cosas como fin en sí mismas, a la elevación hacia todo aquello que es superior a las tareas ordinarias que proporcionan el sustento para sobrevivir en el mundo, sin disfrutar de él; a este tipo de acción lo denominaba también Aristóteles (Ética a Nicómaco, VI; Metafísica, IX) la búsqueda de la práxis teleía, es decir, aquella "acción que tiene el fin en sí misma" (la cultura, la inteligencia), a diferencia de las práxis atelés, cuyo fin utilitario y de aprovechamiento práctico, viene a menudo impuesto, y es distinto a la acción por la que se realiza. Dicha labor de fomentar en la sociedad esa práxis teleía, fue ejemplarmente ejecutada desde el proyecto de las Misiones pedagógicas, donde se aprecia claramente esa preocupación de justicia social cuyo objeto era despertar las conciencias adormecidas por un trabajo rutinario en una sociedad fundamentalmente agrícola, con la aspiración de que aquello estableciese un camino de liberación y de progreso, algo que según Cossío podría alcanzarse a través de la educación, del cultivo del arte, de la inteligencia.

En definitiva, queda de manifiesto que el movimiento pedagógico de la ILE se caracteriza por una acusada vertiente social, según la cual, la educación no puede entenderse como patrimonio de una clase social determinada ni privilegio de una minoría pudiente, sino que -cediendo a sus deseos de democratizacióndebía permanecer abierta a todas las clases sociales, confesiones religiosas e idearios políticos -según su ideal de la libertad de ciencia y de conciencia-, y muy especialmente, a aquellos colectivos que hasta entonces no han disfrutado de sus beneficios, a las fuerzas sociales que estaban marginadas y que -por incuria, abandono o prejuicio social- habían sido excluidas del proceso educativo; a este respecto, recuérdese que en esta época empiezan a asistir a clase las primeras niñas, según el principio de la coeducación, que trataron de implementar por primera vez en España los institucionistas, y que hizo que la educación empezara a entenderse como un principio capital de la vida al que deben acceder todos los seres humanos.

\section{UNA MIRADA PEDAGÓGICA INCLUSIVA EN LA UNIVERSIDAD HA- CIA EL ALUMNADO CON DISCAPACIDAD INTELECTUAL: EL VIDEO PARTICIPATIVO Y EL APS}

De acuerdo con los postulados pedagógicos de Bartolomé Cossío, hemos realizado unas prácticas pedagógicas que se describen a continuación, y que pertenecen a un estudio realizado desde el enfoque de la enseñanza de los derechos humanos, en el marco del Título de Asistente Jurídico de la Universidad Rey 
Juan Carlos, orientado a alumnos con necesidades educativas especiales, donde se ha empleado de modo predilecto la metodología de la pedagogía como obra artística ${ }^{3}$.

Como se ha venido explicando, la pedagogía como arte no es solo una propuesta estética, sino que se trata de toda una forma de comunicación y aprendizaje a través de registros visuales, fotografías, imágenes, dibujos, videos o gráficos, que pueden ser producidos por los propios participantes. El empleo de estos medios audiovisuales para la educación consigue involucrar a educadores y educandos en un proyecto común, donde se genera una socialización y discusión de los conceptos jurídicos leídos en los textos y se plantea una discusión basada en algunos ejercicios de creatividad con respecto a las ideas y las imágenes que han de ser analizadas en clase y recreadas desde nuestro propio imaginario.

Consideramos necesario pues desarrollar una pedagogía que sensibilice a la sociedad en cuanto a los deberes de respeto y solidaridad para con las personas con DI, si es que de verdad se quiere asumir la carga de la realización efectiva de sus derechos. Por ejemplo, haciendo notar que el lenguaje jurídico y las imágenes que utilizamos son portadoras y generadoras de valor cultural y simbólico, que están atravesadas por antagonismo socioeconómicos, raciales y de género que transmiten conocimientos y valores y que, por lo tanto, no son ideológicamente neutras, sino que contienen un gran poder persuasivo porque proyectan y definen la imagen pública de las personas con discapacidad, de modo que pueden ser empleadas para acentuar la discriminación o favorecer la inclusión.

Partiendo de la constatación de este hecho es importante estudiar entonces la estructura de la relaciones simbólicas sociales y narrativas que surgen en los textos fílmicos como recurso pedagógico, para calibrar el grado de agencia que tienen los alumnos y los espectadores en general frente a ellos. Se trata pues de abrir espacios de diálogo e interpretación colectiva, como ejercicio crítico que sea capaz de reconocer en las imágenes las subyacentes huellas del poder, la desigualdad y la ideología.

Para ello, se ha recurrido a la aplicación del método pedagógico conocido como Aprendizaje por Servicio (ApS), que tiene como protagonistas a los estudiantes y a la sociedad y que persigue un cometido de transformación social con

3 Este estudio se ha realizado en el marco del proyecto de innovación docente, de acuerdo con la metodología aprendizaje-servicio (ApS): "Discapacidad: Una cuestión de derecho" financiado por la Oficina de Derechos Humanos de la Universidad Rey Juan Carlos (URJC) durante el periodo (2019-2020), cuya investigadora principal es Marta Albert Márquez. Dicho proyecto tiene continuidad en el Título universitario de "Asistente Jurídico para personas con discapacidad intelectual" que se oferta de manera pionera el año académico 2020-2021 en la citada Universidad. 
un marcado componente crítico. A través de la pedagogía del arte, se busca que el discente tenga una percepción más amplia de su entorno, y no se limite a la mera reproducción normativa de contenidos que se propicia habitualmente en contextos educativos institucionalizados o en los medios de masas. Debemos pues preocuparnos también de poner de relieve "el orden ideológico que condiciona estas formas de lectura, que determinan cuáles son los sujetos y los lugares sociales donde es legítimo mirar y de cuáles es normativo apartar la mirada" (Martínez y Carrión 2019, 82). El objetivo es que sean capaces de visibilizar problemáticas, mediar en situaciones complejas y analizar conflictos de intereses, mediante una intervención y educación activa que pueda modificar y cuestionar así el orden de representación que sostiene dichas narraciones visuales.

Para crear una relación bidireccional entre las distintas producciones visuales y las narrativas de los alumnos, se les invita a crear narrativas propias ligadas a la realidad social de los colectivos o las comunidades - a menudo invisibilizadas o no atendidas por los medios de comunicación- que deseen comunicar. En su mayor parte, la producción de contenidos audiovisuales en los talleres que realizaron los alumnos se fundamentó en la práctica del "reporterismo comunitario, desarrollando propuestas socio educativas y artísticas con el propósito de dinamizar áreas desfavorecidas y promover el desarrollo de redes sociales cooperativas" (Martínez y Carrión 2019, 85).

La logística que siguieron fue la siguiente: en un primer estadio, se trataba de que cada alumno, de acuerdo con sus intereses y afinidades intelectuales, eligiera uno de los derechos fundamentales para el análisis, en torno al cual practicaron una narración sobre su propia realidad, para explorar temas, preocupaciones personales, donde relacionaron los contenidos de la asignatura con casos concretos e incluso contaron historias de vida manera creativa, encontrando así un cauce de expresión, de representación y empoderamiento, para explorar su propia agencia individual y colectiva sobre ese horizonte del cambio social anhelado para las personas con discapacidad intelectual.

El resultado de estos talleres de vídeo fue la producción de varios micro documentales donde cada alumno explicaba como vivía en su propia piel esos conflictos de discriminación o exclusión social por diferentes motivos (económicos, de acceso a la educación, de género o culturales), situándose ante ellos con una mirada autónoma, crítica y responsable. En el desarrollo de esta actividad se propició un lugar de diálogo abierto en que se dio lugar a una nueva generación de nexos, vínculos, conexiones y relaciones inéditas donde se mezclaron: por un lado, las expectativas reales del pensamiento del educando, en conexión directa con su vida (para lo cual hacen uso de sus imaginarios 
personales, de su bagaje, de sus propias imágenes y símbolos culturales), y, por otro lado, los conceptos adquiridos en el marco de las sesiones teóricas sobre derecho, anudando dichos conocimientos a su ámbito personal y colectivo, apropiándose conscientemente de los procesos de representación audiovisual y colocándose en el lugar de su experiencia situada y concreta para establecer nuevos modos posibles de leer la realidad. Al convertirse el educando en el actor principal y protagonista, y no en un mero espectador del hecho educativo (literalmente en lo que hoy se denomina un prosumidor (Zafra 2013, 173) o hacer de quienes son consumidores, también productores, desde una implicación activa y solidaria de la ciudadanía, gracias a un arte social y popular que está al alcance de todos) está representando y visibilizando así del mejor modo posible al colectivo de las personas con discapacidad intelectual, pues en su relato aparecen situaciones que narran, sin mediadores ni tutelas directivas, con su propia imagen, con su cuerpo, con su voz, con los espacios, y las relaciones que establecen con el mundo, aportando toda la emoción, la información y la significación a la narración sobre sus propios derechos, donde se encarnan conexiones con la vida propia, deseos personales de mejora profesional e inestimables horizontes vitales y proyectos de futuro. Gracias al método pedagógico ApS y al uso de las TICs, se sentaron las condiciones de posibilidad para la reconstrucción de la identidad de los discentes, a partir de las reflexiones sobre la propia vivencia desde una perspectiva postestructural, que se tradujo en la generación de nuevas creencias y actitudes gracias al desarrollo e incorporación de nuevos valores. Así pues, frente a la homogeneización global de los imaginarios que se da en los discursos hegemónicos en los medios de comunicación de masas y en algunos modelos tradicionales de educación, consideramos que el empleo de esta metodología se hace cada vez más necesario para multiplicar los espacios propios donde relatar sus propias experiencias y su devenir comunitario y social (Pallarés et. alt. 2020).

En segundo lugar, se procede al visionado colectivo de estos vídeos en clase, actuando así la imagen como una suerte de espejo, que permite mantener la coherencia de las historias que relatamos sobre nosotros mismos y otorgar sentido y orden en las vivencias y al caos de la vida. Se produce así un diálogo horizontal entre docentes y discentes que se relacionan horizontalmente, analizando actitudes, valores, juicio, etc. El visionado de los propios relatos y el de otros compañeros les permite además reactualizar sus propias experiencias a partir de las imágenes, mediante un ejercicio de reconstrucción simbólica, donde son capaces de articular los fragmentos del antes y del después, con el sentido que le queremos otorgar, de manera colaborativa, posibilitando una narración de los procesos relacionales surgidos a partir de las biografías en los 
documentales, a partir de la comunidad educativa referente a la que se pertenece, para poner nuevas metas y fijar mejoras en el marco de la comunidad social.

Después, se procede a su difusión más allá del aula, en las redes sociales. Su amplificación en la sociedad tiene el potencial de generar además un efecto muy interesante en el proceso de creación de la identidad, de socialización y de reconocimiento de uno mismo y del otro, a través de una representación estética y artística en los videos sociales que ellos mismos han creado. Las características educativas de este hecho artístico hacen que se convierta en una herramienta eficaz para el aprendizaje, al crear un espacio colaborativo donde los estudiantes pueden cooperar, elaborar afinidades y poner en común distintas experiencias existenciales, que les unen para presentar hechos o procedimientos que a menudo no pueden presenciarse en directo en las aulas, pero que permiten elaborar diferentes respuestas críticas frente al visionado del documental realizado. En este sentido, resulta muy relevante en este modelo de construcción de sentido y de empoderamiento el hecho de que las personas con discapacidad intelectual dejen de ser objeto de estudio en la mirada del investigador o del jurista, para convertirse ellos mismos en sujetos y protagonistas del relato de sus propias vidas, activando en ello su espíritu crítico y ayudándoles a juzgar y conocer sus derechos, en un sentido personal y también colectivo, como ciudadanos.

Quizá esta sea una de las promisorias aplicaciones que la teoría de la pedagogía del arte de Manuel Bartolomé Cossío tiene en nuestros días: convertir la escuela y el aula universitaria en un contexto educativo y comunicacional, no solamente empleando medios audiovisuales estéticos o artísticos como recursos pedagógicos, sino también convirtiendo a la escuela en un taller y en un laboratorio donde los alumnos participen activamente en la creación de su propio imaginario, mediante la elaboración de documentales propios y videos sociales, desarrollando modelos de construcción de sentido y de educación -no solo en el ámbito escolar o académico- sino también en la esfera social e institucional, pues se espera que el visionado de estos vídeos consiga armar y articular, no solo una respuesta crítica de los estudiantes frente a la esfera pública, sino también una respuesta de la sociedad ante la proyección de ciertos valores y modelos de identificación no hegemónicos que se muestran en esta proyección audiovisual con el enorme poder sugestivo y permanente de sus mensajes, de sus propias historias de vida que resultan ser el principal recurso didáctico y narrativo, estableciendo además un vínculo afectivo y una empatía enorme entre los protagonistas y los espectadores, al mostrarnos patrones de comportamiento que son capaces de influir en el mundo del espectador y, por ende, de la sociedad y que reclaman su propio espacio, sus propios derechos, empezando por el 
derecho al espacio del reconocimiento de su sentido, su voz y su lugar en el ámbito social.

La creación de estos vídeos participativos, como recurso educativo y como herramienta para el acercamiento crítico a la realidad social, les permitió además valorar y resignificar su cultura cotidiana, algo cada vez más relevante si atendemos al marco de una cultura audiovisual cada vez más omnipresente en nuestras sociedades. Pero no se instalaron en la posición de observadores pasivos, sino que pudieron ir más allá de las prácticas situadas y de las imágenes canónicas dadas por los medios de masas, construyendo ellos mismos una alternativa a esos medios, mediante la creación y la comunicación de su pensamiento, con autonomía y con la libertad de expresión y de conciencia, que tanto demandaban los institucionistas para los educandos.

Estas estrategias educativas están especialmente indicadas para personas con DI o con dificultades en la comprensión y producción lingüística, pues permiten expresar significados, emociones y expresiones que difícilmente podrían ser evocadas o recogidas con palabras. La imagen extiende el sentido del relato, y los textos relatados buscan orientaciones que encuentran en la representación gráfica la oportunidad de una comunicación más libre y estimulante. La mayor estimulación cognitiva y el sentido de propósito y de utilidad que viene dado por este tipo de aprendizaje visual en que los participantes construyen su imagen y su identidad, nos parece un incentivo a la creatividad por cuanto siempre se deja en la imagen un margen al sujeto para oponerse o resignificar sus exigencias y derechos.

La necesidad de hacer cognoscibles y enseñables los derechos y deberes a toda la ciudadanía, especialmente a los colectivos más vulnerables, fue lo que inicio y motivó la creación de una metodología y una didáctica derecho, que estuviera ligada a una educación con vocación transformadora, para lo cual era preciso implementar una pedagogía del arte basada en una aproximación democratizadora del derecho.

El cambio radical que esta metodología inclusiva introduce en la educación es una consecuencia de la nueva forma de vivir y de cohabitar el docente con los discentes, un resultado de la emancipación del alumno, que se libera de viejas tutelas, que obedece a impulsos internos, que se dirige a sí mismo y que aspira a tomar parte en la obra social común y que interviene y coopera en el mismo régimen escolar como colaborador de su propia educación, en la línea del principio institucionista del selfgovernment o autogobierno, en un concepto de educación cuyo último sentido tiene solo un límite: la individualidad y la autonomía del alumno. 
Al igual que Cosío, consideramos en este proyecto que la función del profesor en el aula ha de operar como simple artesano o artista de la vida, dentro de una metodología por la cual, él vive, no para ser cada vez más él, sino para hacer que los otros sean, para facilitar que elaboren sus propios discursos y adquieran una voz propia e insustituible. De acuerdo con este paradigma, se ha dejado la puerta abierta para que sean los propios estudiantes quienes elijan los aspectos ético-jurídicos que consideran más relevantes o necesarios en su vida, para su propia formación académica y proyección profesional.

De lo anterior se desprende que, en la óptica de esta perspectiva pedagógica, la actividad más importante ha sido la creación de dinámicas y acciones por las cuales el alumno ha intervenido activamente en el proceso de su propia educación, invitándolo e incitándole constantemente a que sienta, a que haga, a que piense, a que comparta, a que vaya con los ojos bien abiertos por el mundo para enterarse por sí mismo de las cosas, sin esperar una interpretación dogmática por parte del profesor para poder forjarse su propia opinión, sin esperar a que se le den las cosas hechas, sino ayudarle y asistirle para que él mismo las haga, pues de lo contrario, se corre el riesgo de que no abandone jamás los andadores del profesor o del tutor, cuya función ha de ser acogerle y acompañarle y no opacarle en su proceso de formación creativa ${ }^{4}$.

La originalidad de Cossío al adelantar el modelo de escuela activa, que con más o menos profundidad se encuentra formulado en otros métodos pedagógicos de nuestro tiempo, orientó las bases teóricas y la práctica formativa de modelos de educación contemporáneo como la pedagogía de aprendizaje y servicio (ApS), para la cual, efectivamente, no tiene ningún sentido separar al sujeto de la realidad que habita, pues el conocimiento no se centra en conocer, sino en experimentar.

Dicho proyecto puede clasificarse dentro del modelo de diseño curricular crítico o emancipador donde se plantea una racionalidad práctica, guiada por la ética, consistente en una interacción dinámica de la acción y la reflexión, que trata de "construir o reconstruir reflexivamente el mundo social. Se trata de un modelo con un fuerte componente de crítica social y un marcado carácter emancipador" (Pallarès y Chiva 2017, 153) para cual, el punto de partida viene marcado por la desigualdad y por contextos de necesidad social, sobre los que urge

4 Véase a este respecto la interesante idea del acompañamiento, que entronca en este punto con la metodología del ApS, y que se describe en la obra sobre La pedagogía de la presencia (Pallarès y Chiva 2017, 157), donde el docente debe conocer y preocuparse por el alumnado al que acompaña, e interesarse así por sus motivaciones, experiencias, temores, inquietudes y expectativas. 
organizar una prestación de un servicio para un colectivo que se encuentra en desventaja social o en riesgo de exclusión.

En tal sentido, se elaboró esta propuesta educativa cooperativa desde la voluntad de transformación social encaminada a incrementar el bienestar de las personas con discapacidad intelectual y su nivel de inclusión social, así como a la formación, conciencia y sensibilización de la sociedad y de los miembros de la comunidad universitaria en relación con los derechos de una minoría en situación de vulnerabilidad. El objetivo fundamental del proyecto ha sido pues sensibilizar a la comunidad universitaria y a la sociedad en general sobre los derechos de las personas con DI. Por esta razón, un aspecto vital de esta tarea ha consistido en empoderar a las personas con DI para que exijan lo que debería estar garantizado por derecho: su libertad, su derecho a la igualdad y a la dignidad.

La finalidad última de este proyecto educativo ha sido crear conciencia social sobre los abusos del pasado, aportando una dimensión est(ética), es decir, artística y moral, a través de un arte comprometido que sirva para promover, de modo responsable, los derechos humanos. A este respecto, se ha tratado de mejorar la calidad y el principio de igualdad de oportunidades ofrecido por nuestros sistemas educativos, declarando la necesidad de que el alumnado con discapacidad participe en la vida universitaria en igualdad de condiciones que el resto de sus compañeros. El objetivo final es pues vencer esta situación de impotencia derivado de las barreras ambientales, para que puedan adquirir el control sobre sus propias vidas, algo que afecta a otras facetas importantísimas dentro del proceso educativo como la formación en valores y la autoestima de los estudiantes, que ven reforzado su papel en la sociedad y fortalecida la seguridad en sí mismos gracias a formar parte activa de los programas educativos de los que son destinatarios (Cárdenas et. alt. 2017).

Para ello, era necesario conocer y tener muy presente su opinión, la voz de los propios alumnos, que se convirtieron en protagonistas de las acciones formativas y divulgativas diseñadas para cumplir este fin. Más concretamente, entre los objetivos de las actividades y acciones propuestas se encuentran: i). la formación de los alumnos de los jóvenes con DI en la titularidad y ejercicio de los derechos fundamentales de este colectivo, para hacerles conscientes de su papel como ciudadanos activos en una sociedad democrática; ii). el empoderamiento de las personas con DI a través de la adquisición del papel de docentes en talleres de información y sensibilización sobre sus derechos; iii). la formación y sensibilización de la comunidad universitaria en la cuestión de los derechos fundamentales y su ejercicio por parte de las personas con DI, gracias a un espacio abierto a la realidad de la discapacidad procurado por el marco inclusivo 
y de normalización ofrecido por la Universidad Rey Juan Carlos; iv). asimismo, se buscó un mayor impacto en términos de sensibilización social que fuera más allá del marco universitario, para garantizar su amplificación en el tejido social y en la formación de la opinión pública sobre este tema, contribuyendo así a superar los límites y las barreras que los estereotipos sociales sobre la discapacidad intelectual imponen a la sociedad sobre esta condición.

En la actividad se involucraron profesores del área de Filosofía del Derecho como la coordinadora del proyecto, Marta Albert Márquez, con sus alumnos de la asignatura Teoría del Derecho, y por el área Filosofía, participó la profesora Delia Manzanero con sus alumnos de la asignatura Educación Emocional y Social. Además, se implicaron en la actividad los alumnos del máster en Bioética de la URJC. Esto implica dos grados distintos (Derecho y dobles grados vinculados con Derecho), el grado en Educación Infantil y un título de posgrado, además de la participación en la actividad el equipo de profesionales de la Fundación Esfera, compuesto por psicólogos, educadores sociales y terapeutas ocupacionales. Con este equipo se organizaron unos seminarios de trabajo cooperativo entre los alumnos URJC y los alumnos Esfera, y se organizaron dos talleres en la Semana de la Ciencia de 2019. Los talleres fueron titulados "Te enseño mis derechos", y de acuerdo con este lema, fueron liderados por los propios jóvenes con DI participantes en el proyecto 5 .

El hecho de que fueran las propias personas con discapacidad intelectual quienes, en primera persona, expusieran cuáles son sus derechos, tanto a sus iguales (centros ocupacionales, asociaciones o fundaciones) como a través de acciones de sensibilización dirigidas a colectivos diversos (entre los que se encuentran los estudiantes, los entornos sanitarios y los profesionales del derecho), creemos que posee un alcance que contribuye enormemente a la inclusión social del colectivo, por cuanto ofrece una nueva oportunidad de aprendizaje para desarrollar habilidades cognitivas y funcionales, ampliar recursos emocionales y disfrutar de la experiencia, fortaleciendo la seguridad y la autoestima en sí mismos ante la capacidad de formar parte activa del programa.

Además, fruto de dichos talleres, se confeccionaron y publicaron dos Guías: la "Guía de derechos de participación política y social" y la "Guía derechos en el Ámbito Sanitario" (Albert et. alt. 2019) en formato de lectura fácil, sobre los derechos de las personas con DI, donde el arte y la educación artística jugaron un papel esencial para la transformación y acción social en este contexto, porque

5 En las referencias bibliográficas se ofrece un video resumen del evento y algunas noticias en diversos medios de comunicación que se hicieron eco del proyecto Aps. Véase (Talleres 2019). 
los participantes pudieron apreciar y producir arte visual, mediante un programa bien estructurado y apropiado a las necesidades de cada alumno, donde se representaban los derechos fundamentales en lectura fácil con el acompañamiento de imágenes y dibujos para generar espacios de reflexión alrededor del tema de la imagen, con el fin de desarrollar la creatividad y fomentar la capacidad del visual de las personas con DI., contribuyendo así al fortalecimiento de su educación jurídica y artística.

En tal sentido, como se indicaba anteriormente, consideramos que el estudio, a través del arte y de los medios estéticos y creativos, del derecho de la discapacidad en proyectos ApS de vídeos sociales, está relacionado íntimamente con los derechos fundamentales y, muy especialmente, con la efectiva aplicación del principio de igualdad y con el diseño de políticas eficaces que actúen contra toda discriminación. Todas las personas con discapacidad deben tener un sitio, también en las aulas universitarias y en los despachos de abogados, sin que puedan resultar excluidas por prejuicios y estereotipos. Por esta razón, el título se propuso como objetivo motivar a los jóvenes que cursan secundaria para que continúen su formación universitaria, con el fin de que poco a poco se opere la normalización de la presencia de personas con DI en el ámbito universitario y de que la sociedad tome mayor conciencia de la necesidad de ofrecer apoyo para una plena integración psicosocial de este colectivo en el entorno laboral, más aún, en ámbitos laborales que están fuertemente tecnificados, como el ámbito jurídico, donde la comprensión del lenguaje burocratizado de los textos jurídicos no siempre es fácil (De Sousa 2018), a pesar de que la accesibilidad a sus contenidos debe constituir un derecho para todo ciudadano con o sin discapacidad.

De ahí que el Título se enmarque dentro del modelo de formación dual, como nexo de unión entre aulas y empresas y la necesidad de que éstas vean compensadas su colaboración en este ámbito, como herramienta de inserción socio-laboral para personas con discapacidad intelectual (Fajardo 2019, 140). Por esta razón consideramos oportuno subrayar la importancia de la educación profesionalizante en la Universidad, tal y como es llevado a cabo por este Título de manera ejemplar, en el cual, al mismo tiempo se incluyen prácticas en empresas externas, con la colaboración de Deloitte Legal, un referente en auditoría y consultoría; factores ambos centrados en la consideración del empleo como elemento esencial para el desarrollo de una vida personal y social normalizada y como un factor fundamental de inclusión para personas con DI.

Al mismo tiempo, este promisorio modelo de trabajo ha representado para los docentes implicados en este proyecto una oportunidad de mejora y de innovación en nuestra actividad educativa, una oportunidad para buscar alternativas 
y nuevas formas de actuación pedagógica, para lo cual ha sido necesario introducir mecanismos de compensación y adaptación y adaptaciones curriculares con elementos de acceso que permitan a los alumnos alcanzar niveles de igualdad con sus compañeros.

Por su parte, para los estudiantes con DI. el proyecto representó una mejora significativa en su vida cotidiana, y puso de manifiesto que la ciudadanía solo puede ejercerse desde el conocimiento y la conciencia de la titularidad de los derechos, con una pedagogía inclusiva que los haga cognoscibles de, por y para ellos. Por eso pensamos que la accesibilidad cognitiva que nos procura la pedagogía del arte debe ser ampliamente implementada pues el derecho a entender y a ser entendido, cuando se trata de derechos, es una exigencia básica del Estado de Derecho. Si la educación en derechos humanos es un asunto de interés público, ésta debe abordarse colectivamente como cosa pública, en situaciones participativas y prácticas pedagógicas construidas de manera accesible para todos, donde se puedan explorar los potenciales democratizadores de las prácticas mediáticas para el ámbito educativo y social.

\section{CONCLUSIONES}

En este artículo hemos tratado de mostrar la fecunda utilidad de la pedagogía como arte por su eficacia demostrada en la adquisición de contenidos relacionados con el derecho por parte de personas con discapacidad intelectual, donde se empleó el método del Video participativo en un proyecto de ApS, como la herramienta de cambio más eficaz para dar respuesta a alumnos con necesidades educativas especiales, para promover el pensamiento inductivo y la capacidad de establecer conexiones y relaciones críticas entre los mensajes visuales y la intencionalidad de la imagen, buscando así el desarrollo de un pensamiento divergente y de la creatividad del discente.

Para la consecución de tal fin es necesario expandir la educación hacia este nuevo ámbito artístico, capaz de explorar de manera reflexiva nuevos recursos y metodologías educativas dirigidas a desarrollar procesos de alfabetización visual para entender críticamente el alcance estético y creativo de estos métodos pedagógicos. En particular, hemos explorado la utilización de estrategias visuales (fundamentalmente el vídeo participativo, y como un proceso de experimentación, aprendizaje y emancipación -fundamentado en la pedagogía del arte de M.B. Cossío y en la teoría del experimentalismo democrático de J. Dewey (1938) - como un recurso metodológico especialmente adecuado para aquellas 
personas que, por distintas razones, no tienen un nivel lingüístico comunicativo desarrollado o tienen dificultades con la lectoescritura, como es el caso de algunas personas con discapacidad intelectual.

En la actualidad son muchos los niños y los jóvenes con DI que experimentan barreras de participación, de exclusión y de segregación durante su proceso de escolarización, y que son abocados posteriormente a otro muro de limitación en el ámbito universitario, enfrentándose desde la infancia al rechazo social, al fracaso y a experiencias negativas que lo desvalorizan y frustran. Las bajas expectativas sociales y los condicionamientos culturales -como los presentes en países que tienen la discriminación, la ignorancia, la indiferencia y la intolerancia como atributos inescindibles de su estructura ideológica- y los prejuicios sociales hacia la persona con discapacidad, representan el punto de partida de un círculo vicioso que limita significativamente sus posibilidades, y que le hace caer fácilmente en la falta de autoestima y en la desesperanza de creer que es imposible conseguir un empleo (Suriá et. alt. 2016, 2570). Ello nos ha motivado a reorganizar nuevos procesos de enseñanza y de aprendizaje orientados a este colectivo, para reducir la exclusión en y desde la educación. Esto supone cambios y modificaciones estructurales en el contenido, accesos y estrategias docentes, e introducir una visión de responsabilidad y compromiso social con el fin de educar en la diversidad, el respeto y la valoración de la autonomía individual de los propios educandos.

Estamos pues ante una metodología inclusiva y una propuesta pedagógica que, si bien se diseñó inicialmente para una intervención educativa concreta, consideramos que se puede aplicar con éxito en cualquier programa académico de educación formal universitaria que se proponga como objetivo resaltar la importancia de la pedagogía del arte y del aprendizaje de conceptos básicos audiovisuales a través de medios estéticos y artísticos para desarrollar su capacidad creativa y de análisis del discente, y para proporcionar una visión más inclusiva y omnicomprensiva de las realidades y experiencias o problemas vitales que acucian a ciertos colectivos y, en general, a toda una sociedad conectada que se quiera cada vez más igualitaria y justa.

Por eso consideramos de gran relevancia la existencia de este tipo de proyectos de innovación educativa a través de la creatividad, como los aquí reseñados, por su labor en la sensibilización y concientización sobre las necesidades de apoyo educativo de las personas con DI con base en la pedagogía del arte, pues consideramos que muchas de las barreras presentes en este contexto se deben, en gran medida, a la falta de preparación o conciencia de la opinión pública 
y de los poderes públicos en la comprensión genérica o particular de las necesidades específicas de la discapacidad.

\section{REFERENCIAS BIBLIOGRÁFICAS}

Altamira y Crevea, R. 2015. Giner de los Ríos, Educador. Edición crítica con Estudio Preliminar de Delia Manzanero. Analecta Editorial: Pamplona.

Bourdieu, P. 2009. Los herederos: los estudiantes y la cultura. Buenos Aires: Siglo XXI Editores Argentina.

Cárdenas, R.; Barriga, A. P.; Lizama, J. I. 2017. "La expresión artística como estrategia didáctica para el desarrollo de la afectividad y la autoestima en una persona con Discapacidad Intelectual y Síndrome Alcohólico Fetal (SAF)”, Arte, individuo y sociedad, Vol. 29: 205-222.

Cossío, M. B. 1879. "El arte de saber ver", Boletín de la Institución Libre de Enseñanza [en adelante BILE], Año III, nº 65.

Cossío, M. B. 1919. "El decreto de autonomía universitaria”, BILE, XLIII, tomo I: $174-177$.

Cossío, M. B. 1966. De su jornada (2 $2^{\mathrm{a}}$ ed.). Madrid: Aguilar.

De los Ríos Urruti, F. 1926. "El valor de la educación. Sentido y alcance de la socialización de la enseñanza". En El sentido humanista del Socialismo, Id.,

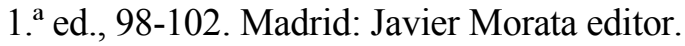

De Sousa Santos, B. 2018. Construyendo las epistemologías del sur: para un pensamiento alternativo de alternativas, compilado por M. P. Meneses [et al.], $1^{\text {a }}$ ed., Ciudad Autónoma de Buenos Aires: CLACSO.

Dewey, J. 1938. Experience and education. Nueva York: Macmillan.

Fajardo, C. M. 2019. "Educación inclusiva, formación dual universitaria y cláusulas sociales", en: Discapacidad Intelectual y Capacidad de Obrar. De la sustitución de la voluntad al apoyo en la toma de decisiones, Juana Morcillo (Dir.). Valencia: Tirant Lo Blanch.

Giner de los Ríos, F. 1917. “¿Cuándo nos enteraremos?”, BILE, XLI, tomo I.

Gómez García, M. N. 1983. Educación y pedagogía en el pensamiento de Giner de los Ríos. Anales de la Universidad Hispalense, serie Filosofía y Letras, $\mathrm{n}^{\circ}$ 67. Sevilla: Secretariado de publicaciones de la Universidad de Sevilla.

Jiménez Landi, A. 1996. La Institución Libre de Enseñanza y su ambiente, 4 vols. Madrid: Editorial Complutense.

Los Fideicomisarios de Sanz del Río. 1871. "Nota de advertencia". En Ideal de la Humanidad para la vida, de K. Ch. F. Krause, con introducción y comentarios de Julián Sanz del Río, $2^{\mathrm{a}}$ ed. Madrid: Imprenta de F. Martínez García.

Manzanero, D. 2016. El legado jurídico y social de Giner, con prólogo de Pedro Álvarez Lázaro. Colección ILKM. Madrid: Publicaciones Universidad Pontificia Comillas. 
Martínez, S.; Carrión, E. 2019. "Participatory video and visual literacy: Challenges and opportunities for social and educational change", Obra digital: revista de comunicación, $\mathrm{N}^{\circ}$. 17: 77-91. https://doi.org/10.25029/od. 2019.242

Maya, J. y Patiño. 2020. "Propiedades de las representaciones en diseño: una exploración interdisciplinaria de su rol funcional". Revista KEPES, Año 17, $\mathrm{n}^{\circ}$. 21: 17-60. https://dx.doi.org/10.17151/kepes.2020.17.21.2

Meix Cereceda, P. 2014. El derecho a la educación en el sistema internacional y europeo. Valencia: Tirant Monografías.

Nieto, A., 1933. "El sentido social de la escuela", BILE, LVII, t. I: 321-324.

Otero Urtaza, E., Manuel Bartolomé Cossío: pensamiento pedagógico y acción educativa, Madrid: Centro de Publicaciones del Ministerio de Educación y Ciencia: CIDE, 1994.

Pallarès, M., Villalobos, J. V., Hernández, J. D., Cabero, I. 2020. "Pedagogía con carácter: aproximación a la disciplina pedagógica como campo de reflexión del sujeto de la educación a partir de Ricoeur", Bajo Palabra. Revista de Filosofia, $\mathrm{n}^{\mathrm{o}}$ 24: 525-546. https://doi.org/10.15366/bp.2020.24.026

Pallarès Piquer, M. y Chiva Bartoll, O. 2017. La pedagogía de la presencia. Tecnologías digitales y aprendizaje-servicio. Barcelona: Editorial UOC.

Revista El Socialista. 1926. "La obra de Giner de los Ríos. El cincuentenario de la Institución Libre de Enseñanza", BILE, L, tomo I: 382.

Suriá, R., Rosser, A. Villegas, E. 2016. "Universidad y discapacidad: expectativas laborales y autoimagen entre los universitarios", Psicología y educación: presente y futuro: $2564-2571$.

Talleres "Te enseño mis derechos", 2019. Véase un video resumen del evento: https://www.youtube.com/watch?v=xej7NMd_250 y algunas noticias en diversos medios de comunicación que se hicieron eco del evento: http://www.aldialeganes.es/noticias/leganes-local/3676/fundacion-esfera-y-la-urjc-elaboranlasprimeras-guias-de-derechos-para-personas-con-discapacidad- $/$

Zafra, R. 2013. (H)adas. Mujeres que crean, programan, prosumen y teclean, Madrid: Páginas de espuma.

Viteri, H. 1918. "El maestro Giner de los Ríos", BILE, XLII, t. II: 282-288.

VV.AA. 1876. Bases y Estatutos de la Institución Libre de Enseñanza. Aprobados interinamente por la Junta general de suscriptores el día 31 de mayo y autorizados por real orden de 16 de agosto de 1876.

Delia Manzanero Facultad de Ciencias Jurídicas y Sociales Universidad Rey Juan Carlos de Madrid Paseo de los Artilleros, 38 28032 Madrid (España) https://orcid.org/0000-0002-6895-1254 